\title{
Mycophenolate mofetil versus Rapamycin in Han: SPRD rats with Polycystic Kidney Disease
}

\author{
TONG ZHANG ${ }^{1}$, LI WANG ${ }^{1}$, XISHAN XIONG ${ }^{1}$, ZHIGUO MAO $^{1}$, LIMING WANG ${ }^{2}$, \\ and CHANGLIN MEI ${ }^{1 *}$
}

\author{
${ }^{1}$ Division of Nephrology, Nephrology Institute of PLA, Changzheng Hospital, Second Military Medical \\ University, Shanghai 200003, China \\ 2 Organ Transplantation institute of PLA, Changzheng Hospital, Second Military Medical University, \\ Shanghai 200003, China
}

\begin{abstract}
Objective: We aimed to explore the effect of Mycophenolate mofetil (MMF) on loss of renal function and cyst progression compared to rapamycin in Han: SPRD rats. We also sought to assess whether the effect of combination therapy of MMF plus rapamycin was better than that of monotherapy. Methods: Sixty heterozygous $(\mathrm{Cy} /+)$ and littermate control $(+/+)$ male Han: SPRD rats were weaned at 4 weeks of age, then divided into four groups randomly to receive different treatments by intragastric administration for 2 months: vehicle-treated group as control, MMF-treated group $(20 \mathrm{mg} / \mathrm{kg} /$ day $)$, rapamycin-treated group (2mg/kg/day), and MMF+Rapa- treated group (MMF $20 \mathrm{mg} / \mathrm{kg} /$ day plus Rapamycin $2 \mathrm{mg} / \mathrm{kg} / \mathrm{day}$ ). Results: After 2 months of treatment, rapamycin caused a $22 \%$ decrease in body weight in comparison to the control group, whereas MMF had no significant effect on weight gain. The steady increase of BUN in $\mathrm{Cy} /+$ rats was reduced by $15 \%$ in $\mathrm{MMF}$-treated $\mathrm{Cy} /+$ rats. However, rapamycin and combination therapy reduced BUN by $42 \%$ and $43 \%$, respectively. CCr was $0.93 \pm 0.11 \mathrm{ml} / \mathrm{min}$ in vehicle-treated $\mathrm{Cy} /+\mathrm{rats}, 1.67 \pm 0.23 \mathrm{ml} / \mathrm{min}$ in $\mathrm{MMF}$-treated Cy/+ rats $(P<0.05), 1.72 \pm 0.44 \mathrm{ml} / \mathrm{min}$ and $1.83 \pm 0.21 \mathrm{ml} / \mathrm{min}$ in rapamycin- and $\mathrm{MMF}+\mathrm{Rapa}$-treated $\mathrm{Cy} /+\mathrm{rats}$, respectively $(P<0.01)$. Cyst volume density was $57.1 \%$ in vehicle-treated $\mathrm{Cy} /+$ rats, $45.2 \%$ in $\mathrm{MMF}$-treated $\mathrm{Cy} /+$ rats $(P<0.05), 32.9 \%$ and $37.7 \%$ in rapamycin- and $\mathrm{MMF}+\mathrm{Rapa}-$ treated $\mathrm{Cy} /+$ rats, respectively $(P<0.01)$. MMF markedly ameliorated interstitial inflammation and fibrosis. Rapamycin showed a similar effect on interstitial inflammation and fibrosis, but to a lesser degree. Conclusion: MMF is more tolerable than rapamycin and can retard deterioration of renal function in Han: SPRD rats, though its effect is weaker than that of rapamycin. Combination therapy does not exert more favorable effect than monotherapy.
\end{abstract}

Key terms: ADPKD, Han: SPRD rat, mycophenolate mofetil, rapamycin.

\section{INTRODUCTION}

Autosomal dominant polycystic kidney disease (ADPKD) is one of the most common human monogenic diseases, with an incidence of 1 in 500 to 1 in 1000, which affects 12 million people worldwide, and 1.5 million people in China. It is characterized by the progressive formation and enlargement of multiple renal cysts. Approximately $50 \%$ of patients develop renal insufficiency in the fifth and sixth decades of life (Wilson, 2004; Dai \& Mei, 2006).
Until now, treatment of ADPKD has been limited to dealing with complications (i.e. hypertension and renal failure), as there is no specific therapy currently available to slow the progression of this disease. However, advances in the understanding of cystogenesis and availability of genetically related animal models provide opportunities to develop effective treatments. Since the accelerated proliferation of cells that line cyst cavities plays a crucial role in the progress of ADPKD, drugs that can inhibit epithelial cell proliferation may be promising

\footnotetext{
* Corresponding author: CHANGLIN MEI, Division of Nephrology, Nephrology Institute of PLA, Changzheng Hospital, 415 Fengyang Road, Shanghai 200003, China. E-mail: nephrologist@163.com Tel: +86-21-81885411, Fax: +86-21-81885411.
} 
candidates for treatment of ADPKD. Rapamycin is an immunosuppressant inhibited activation of the mTOR, a key regulatory kinase of growth and proliferation. It has been used to prevent graft rejection following renal transplantation, and also used in coated stents to prevent coronary artery restenosis after angioplasty (Morice et al., 2002). It has been shown that inhibition of mTOR with rapamycin or everolimus effectively reduces cyst growth and loss of renal function in various animal models of PKD, including Han: SPRD rats (Wahl et al., 2006; Wu et al., 2007; Tao et al., 2005). Moreover, rapamycin has been used in human clinical trials (Serra et al., 2007). However, evidence for rapamycinassociated nephrotoxicity has been accumulating in the transplant community in recent years. The administration of rapamycin may exacerbate pre-existing or newly occurring renal lesions (Marti et al., 2005). Thus, we wonder whether another immunosuppressant also has a protective effect on ADPKD, but with little toxicity.

Mycophenolate mofetil (MMF), a new immunosuppressive drug, has been a safe and well-tolerated agent used in preventing renal allograft rejection. MMF strongly inhibits both $\mathrm{T}$ - and $\mathrm{B}$ lymphocyte proliferation resulting from inhibition of the rate-limiting enzyme in the de novo pathway of purine synthesis. Recent evidences suggest that MMF is capable of inhibiting the proliferation of non-immune cells, such as smooth muscle cells, renal tubular cells, mesangial cells and fibroblasts (Baer et al., 2000; Dubus et al., 2002; Hauser et al., 1999; Azzola et al., 2004). MMF is also well-known for its antiinflammatory properties. It reduces renal inflammation, oxidative stress, and arterial pressure in rats with lead-induced hypertension (Bravo et al., 2007), restricts lymphocyte and macro-prophage proliferation and limits the expression of adhesion molecules in experimental diabetic nephropathy (Utimura et al, 2003). In ischemia reperfusion injury of rat kidneys, MMF pre-treatment reduces tissue injury in part through a down regulation of intercellular adhesion molecule 1 (ICAM-1) expression and a reduction of tissue macrophage and lymphocyte infiltration (Ventura et al., 2002).MMF has been used successfully to treat a variety of glomerular diseases, but its effect on preventing ADPKD progression remains poorly investigated. Based on our published data that MMF effectively inhibited cyst-lining epithelial cells proliferation, as well as induced cell apoptosis in vitro (Zhang et al., 2008), we hypothesized that MMF might be an effective oral drug to slow ADPKD.

In the present study, we used Han: SPRD rat model of PKD to explore the effect of MMF on loss of renal function and cyst progression compared to rapamycin. We also investigated whether the effect of combination therapy of MMF plus rapamycin was better than that of monotherapy.

\section{METHODS}

\section{Animals}

The study was conducted in heterozygous $(\mathrm{Cy} /+)$ and normal littermate control $(+/+)$ Han: SPRD rats, an established animal model of autosomal dominant inherited polycystic kidney disease. All the $\mathrm{Cy} /+$ and normal rats studied were males since the disease progresses faster in male rats than in females. A colony of Han: SPRD rats was established in our animal care facility from a litter obtained from the Mayo Clinic (Rochester, MN, USA). The study protocol conformed to the Guiding Principles in the Care and Use of Laboratory Animals. Rats had free access to tap water and standard rat diet.

\section{Sample size calculation}

The comparison among 4 groups would be made with a significance level of $\alpha=0.05$, and with a power of $90 \%(\beta=0.10)$. Based on data of our preliminary experiment, we assumed that the standard deviation within each group was $S=3$ and that the means for the four groups were given by $\bar{X}=15, \bar{X}=$ $13, \bar{X}=9$, and $\bar{X}=8$. We used the equation below to calculate sample size of each 
group. In this equation, $\Psi$ value was found in the relevant statistic table, $k=4$, and finally, calculated $\mathrm{n}$ was 4 .

$$
\mathrm{n}=\Psi^{2}\left(\sum S_{i}^{2} / k\right) /\left[\sum\left(\overline{\mathrm{X}}_{i}-\overline{\mathrm{X}}\right)^{2} /(k-1)\right]
$$

Because the study was conducted in heterozygous $(\mathrm{Cy} /+)$ and normal littermate control $(+/+)$ Han: SPRD rats, and the ratio of $(\mathrm{Cy} /+)$ to $(+/+)$ was nearly $2: 1$, the minimal sample size of each group was 12 , in order to show differences between $(\mathrm{Cy} /$ $+)$ or $(+/+)$ rats of the four groups.

\section{Experimental protocol}

Sixty male $\mathrm{Cy} /+$ and $+/+$ rats were weaned at 4 weeks of age, then divided into four groups randomly: vehicle-treated group as control $(n=15)$, MMF-treated group (20mg/ $\mathrm{kg} /$ day, $\mathrm{n}=15)$, rapamycin-treated group ( $2 \mathrm{mg} / \mathrm{kg} / \mathrm{day}, \mathrm{n}=15)$, and $\mathrm{MMF}+\mathrm{Rapa}$ treated group (MMF $20 \mathrm{mg} / \mathrm{kg} /$ day plus Rapamycin $2 \mathrm{mg} / \mathrm{kg} / \mathrm{day}, \quad \mathrm{n}=15)$. Mycophenolate mofetil (CellCept ${ }^{\circledR}$, Roche Laboratories Inc., Switzerland) and rapamycin (Rapamune ${ }^{\circledR}$ oral solution, Wyeth Pharmaceuticals Inc., USA) were prepared in $0.5 \%$ carboxymethylcellulose (Sigma, St. Louis, MO), and given by intragastric administration with the volume within $1 \mathrm{ml}$ per day. The doses were based on previous experiments (Wahl et al., 2006; Ventura et al., 2002) and our preliminary experiment. Blood was drawn from the tail veins every month. Weight gain was measured during the study period to evaluate drug tolerance. Since the nutritional support of each group was similar, weight gain was a reflection of drug tolerance. After 2 months treatment, rats were anaesthetized by intraperitoneal injection of pentobarbital sodium $(50 \mathrm{mg} / \mathrm{kg}$ body weight), and kidneys were removed and weighed. Slices of each kidney were fixed in $4 \%$ paraformaldehyde and embedded in paraffin for histological examinations.

\section{Functional Study}

Serum urea nitrogen (BUN) and creatinine ( $\mathrm{SCr}$ ) were measured to evaluate protective effects. At the end of the study, rats were placed in metabolic cages with free access to water, and urine was collected over a 24$\mathrm{h}$ period to obtain urinary volume. Then urine creatinine ( $\mathrm{UCr}$ ) and a comparative blood test were taken. All samples were analyzed by HITACHI 7080, an automatic biochemistry analyzer fabricated by HITACHI, Japan. The creatinine clearance rate $(\mathrm{CCr})$ was used to estimate glomerular filtration rate (GFR).

$C C r(m l / \mathrm{min})=\frac{\mathrm{UCr} \times 24-\mathrm{h} \text { urinary volume }(\mathrm{ml})}{\mathrm{SCr} \times 24 \times 60 \mathrm{~min}}$

\section{Histological study}

Hematoxylin-eosin-stained (HE) sections were used to determine the cyst volume density (CVD). Measurements were taken in the renal cortex of $\mathrm{Cy} /+$ rats because the cysts mainly involve the cortex (Cowley et al., 1993). This was performed by a reviewer, blinded to the identity of the treatment modality, using point-counting stereology (Mathieu et al., 1981). Briefly, the presence of cysts was determined at the crossing points on a $10 \times 10$ division grid. One hundred points in 5 to 10 high power fields of each section were counted in areas of the cortex at 90, 180, and 270 degrees from the hilum to guard against reviewer bias and field selection variation.

Renal inflammation was evaluated by a semi-quantitative analysis based on calculating the proportion of cortex infiltrated by inflammatory cells in PAS stained sections (Inflammatory index). Renal fibrosis was evaluated by a semiquantitative analysis based on calculating the proportion of fibrosed cortex in Masson's trichome stained sections (Fibrosis index ): Using two PAS and two Masson's trichrome-stained sections from each animal, six random low-power $(\times 100$ magnification) photographs were taken of each section and morphometrically analyzed using point counting.

\section{Statistical analysis}

Data were presented as means \pm SD. Groups were compared using one-way 
ANOVA with a post-test according to Newman-Keuls and $t$ test. Results were considered statistically significant at $P$ $<0.05$.

\section{RESULTS}

\section{Tolerance evaluation}

During the two-month period, two rats treated with rapamycin died and three rats treated with MMF+Rapa died. However, none of the rats treated with vehicle or MMF alone died.

Body weight increased steadily in the four groups, but rapamycin-treated rats $(n=13)$ and $M M F+R a p a-t r e a t e d$ rats $(n=12)$ had less weight gain than did the control $(n=15)$ and MMF-treated group $(n=15)$ since the fourth week. After two months of treatment, in comparison to control group, rapamycin-treated rats and $\mathrm{MMF}+\mathrm{Rapa}-$ treated rats had a $22 \%$ and $23 \%$ decrease in body mass respectively, whereas there were no significant differences between $\mathrm{Cy} /+$ and $+/+$ rats in the same group (Figure 1). Despite the loss in body weight, all of the rats seemed healthy during the study and without differences in daily food intake.

\section{Therapeutic effects evaluation}

The baseline characters of blood urea nitrogen (BUN), serum creatinine $(\mathrm{SCr})$, and $\mathrm{CCr}$ levels were similar among the four groups. After two months of treatment, BUN and $\mathrm{SCr}$ levels were within normal limits in $+/+$ rats of the four groups, but increased progressively in vehicle-treated $\mathrm{Cy} /+$ rats $(\mathrm{n}=10)$. MMF reduced $\mathrm{BUN}$ by $15 \%$ in $\mathrm{Cy} /+$ rats $(\mathrm{n}=10)$ compared to vehicle-treated $\mathrm{Cy} /+$ rats. However, rapamycin and combination therapy reduced BUN by $42 \%(n=9)$ and $43 \%(n=8)$ in $\mathrm{Cy} /+$ rats, respectively. Similarly, $\mathrm{SCr}$ level of MMF- treated $\mathrm{Cy} /+$ rats increased less than vehicle-treated ones $(P<0.05)$. Rapa- and $\mathrm{MMF}+\mathrm{Rapa}$-treated $\mathrm{Cy} /+$ rats obviously reduced $\mathrm{SCr}$ level compared to the control group $(P<0.01)$. There were no significant differences of $\mathrm{BUN}$ and $\mathrm{SCr}$ levels between Rapa- and $\mathrm{MMF}+\mathrm{Rapa}-$ treated $\mathrm{Cy} /+$ rats. $\mathrm{CCr}$ was higher in $\mathrm{MMF}-$, Rapa-, and $\mathrm{MMF}+\mathrm{Rapa-treated} \mathrm{Cy} /+$ rats than in vehicle-treated $\mathrm{Cy} /+$ ones (Table 1 ).

In comparison to vehicle-treated $\mathrm{Cy} /+$ rats, rapamycin and $\mathrm{MMF}+\mathrm{Rapa}$ reduced the 2-kidney/ total body weight $(2 \mathrm{~K} / \mathrm{TBW})$ ratio by $17 \%$ and $12 \%$ in $\mathrm{Cy} /+$ rats, respectively. MMF alone did not decrease the $2 \mathrm{~K} / \mathrm{TBW}$ ratio significantly, though demonstrated a trend of lowering the $2 \mathrm{~K} /$ TBW ratio. There were no differences in the $2 \mathrm{~K} / \mathrm{TBW}$ ratio of $+/+$ rats among the four groups (Figure 2).

Histological examination demonstrated a dramatic reduction in number and size of renal cysts in rapamycin and $\mathrm{MMF}+\mathrm{Rapa}$ treated $\mathrm{Cy} /+$ rats compared to vehicletreated ones. MMF could also reduce cyst growth of $\mathrm{Cy} /+$ rats, but to a lesser degree

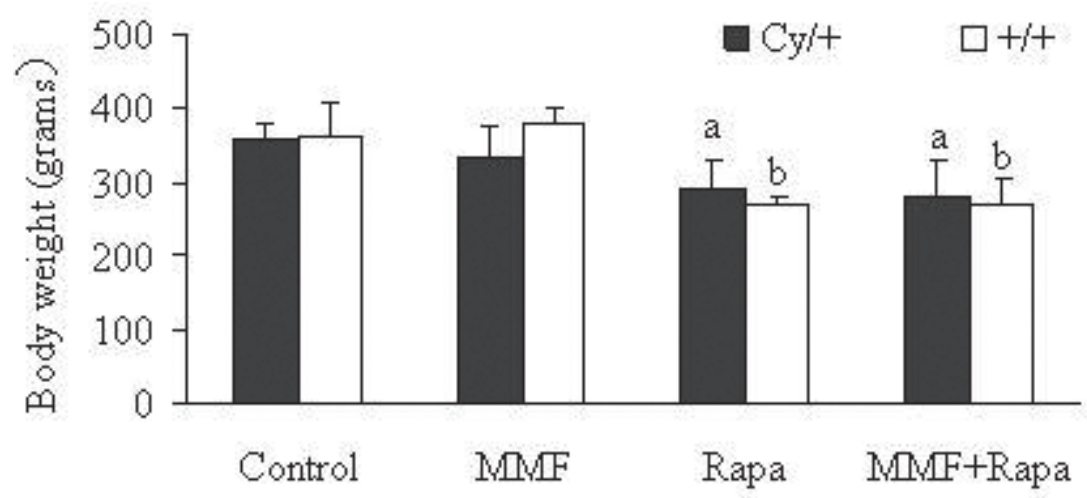

Figure 1: Effects of MMF, rapamycin (Rapa) and combination therapy on body weight of Han: SPRD rats after two months of treatment. a $P<0.01$ versus control group $\mathrm{Cy} /+$ rats, b $P<0.01$ versus control group $+/+$ rats. 
TABLE 1

Effects of MMF, rapamycin (Rapa) and combination therapy on renal function

\begin{tabular}{|c|c|c|c|c|c|c|}
\hline & \multicolumn{2}{|c|}{$\mathrm{BUN}(\mathrm{mmol} / \mathrm{L})$} & \multicolumn{2}{|c|}{$\mathrm{SCr}(\mathrm{mmol} / \mathrm{L})$} & \multicolumn{2}{|c|}{$\mathrm{CCr}(\mathrm{ml} / \mathrm{min})$} \\
\hline & baseline & 2 months & baseline & 2 months & Baseline & 2 months \\
\hline \multicolumn{7}{|l|}{ Control group } \\
\hline $\mathrm{Cy} /+(\mathrm{n}=10)$ & $7.89 \pm 0.77$ & $15.45 \pm 0.97$ & $12.45 \pm 0.38$ & $37.76 \pm 3.71$ & $1.89 \pm 0.13$ & $0.93 \pm 0.11$ \\
\hline$+/+(n=5)$ & $7.84 \pm 0.72$ & $8.50 \pm 0.62$ & $12.32 \pm 1.13$ & $22.1 \pm 0.52$ & $1.91 \pm 0.12$ & $2.12 \pm 0.37$ \\
\hline \multicolumn{7}{|l|}{ MMF group } \\
\hline $\mathrm{Cy} /+(\mathrm{n}=10)$ & $7.94 \pm 1.41$ & $13.14 \pm 2.9^{\mathrm{a}}$ & $12.19 \pm 1.24$ & $26.67 \pm 4.41^{\mathrm{a}}$ & $1.88 \pm 0.21$ & $1.67 \pm 0.23^{\mathrm{a}}$ \\
\hline$+/+(n=5)$ & $7.48 \pm 0.53$ & $8.22 \pm 0.34$ & $12.57 \pm 0.78$ & $23.16 \pm 0.92$ & $1.95 \pm 0.15$ & $2.16 \pm 0.35$ \\
\hline \multicolumn{7}{|l|}{ Rapa group } \\
\hline $\mathrm{Cy} /+(\mathrm{n}=9)$ & $7.81 \pm 0.62$ & $8.91 \pm 0.84 \mathrm{bc}$ & $12.63 \pm 1.52$ & $25.34 \pm 4.85^{b}$ & $1.94 \pm 0.14$ & $1.72 \pm 0.44^{b}$ \\
\hline$+/+(n=4)$ & $7.92 \pm 0.14$ & $8.23 \pm 1.1$ & $12.62 \pm 0.94$ & $21.33 \pm 1.57$ & $2.01 \pm 0.20$ & $2.33 \pm 1.57$ \\
\hline \multicolumn{7}{|c|}{ MMF+Rapa group } \\
\hline $\mathrm{Cy} /+(\mathrm{n}=8)$ & $7.62 \pm 1.31$ & $8.78 \pm 0.75 \mathrm{bc}$ & $12.42 \pm 1.47$ & $22.42 \pm 2.01^{b}$ & $1.92 \pm 0.11$ & $1.83 \pm 0.21 \mathrm{~b}$ \\
\hline$+/+(n=4)$ & $7.51 \pm 0.53$ & $8.12 \pm 0.31$ & $12.84 \pm 1.43$ & $21.13 \pm 1.3$ & $1.89 \pm 0.13$ & $2.13 \pm 0.33$ \\
\hline
\end{tabular}

a $P<0.05$ versus control group $\mathrm{Cy} /+$ rats, b $P<0.01$ versus control group $\mathrm{Cy} /+$ rats, c $P<0.01$ versus $\mathrm{MMF}-$ treated group $\mathrm{Cy} /+$ rats.

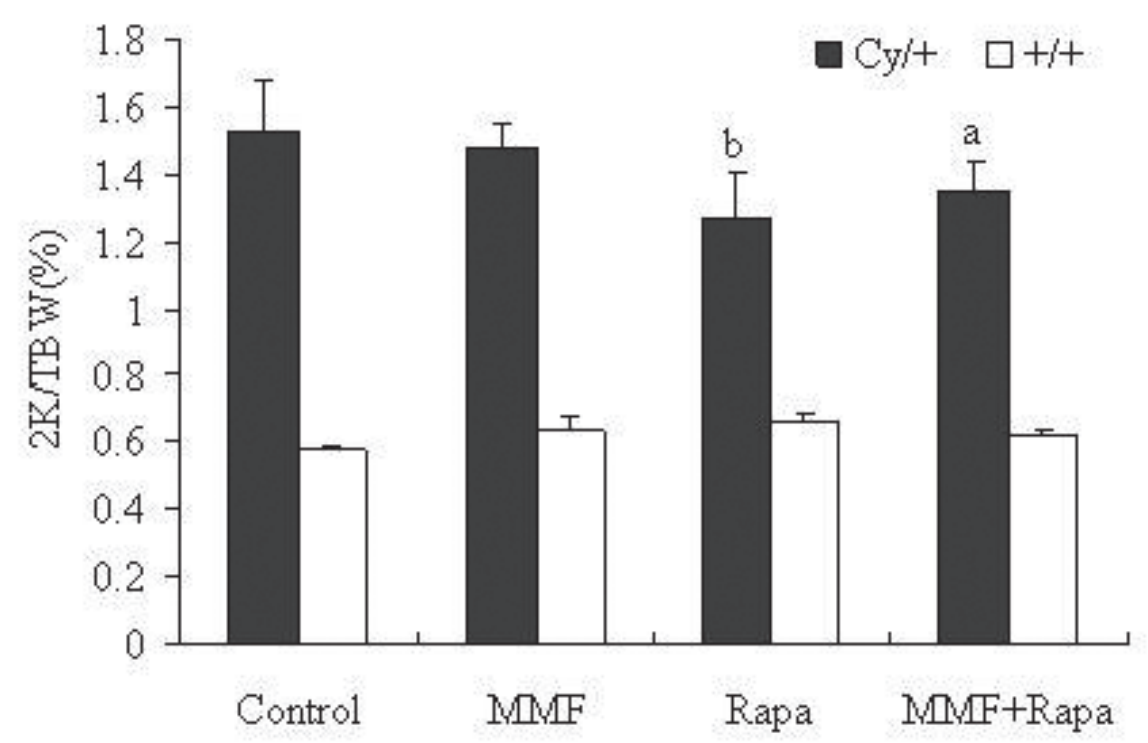

Figure 2: Effects of MMF, rapamycin (Rapa) and combination therapy on the two-kidney /total body weight $(2 \mathrm{~K} / \mathrm{TBW}$ ) ratio. a $P<0.05$ versus control group. b $P<0.01$ versus control group. 
than rapamycin and $\mathrm{MMF}+\mathrm{Rapa}$. Wild-type $+/+$ kidneys showed no difference in histology among the four groups (Figure 3). Cyst volume density (CVD) was $57.1 \%$ in vehicle-treated $\mathrm{Cy} /+$ rats, $45.2 \%$ in $\mathrm{MMF}$ treated $\mathrm{Cy} /+$ rats $(P<0.05$ versus vehicletreated $\mathrm{Cy} /+), 37.7 \%$ and $32.9 \%$ in rapamycin- and $\mathrm{MMF}+\mathrm{Rapa}$ - treated $\mathrm{Cy} /+$ rats respectively $(P<0.01$ versus vehicletreated $\mathrm{Cy} /+)$.

In $\mathrm{Cy} /+$ rats, mononuclear infiltration was present in the renal interstitium as evidenced by morphometric analysis of PAS-stained sections. The inflammatory infiltration was inhibited by MMF, rapamycin, and combination therapy. The inflammatory index of MMF-treated $\mathrm{Cy} /+$ rats was the lowest among the four groups. On the other hand, Masson's trichromestained sections of kidneys were used to assess interstitial fibrosis. MMF markedly ameliorated the interstitial fibrosis compared with vehicle-treated $\mathrm{Cy} /+$ rats, rapamycin and combination treatment also can decrease the fibrosis index, but to a lesser degree than MMF (Table 2).
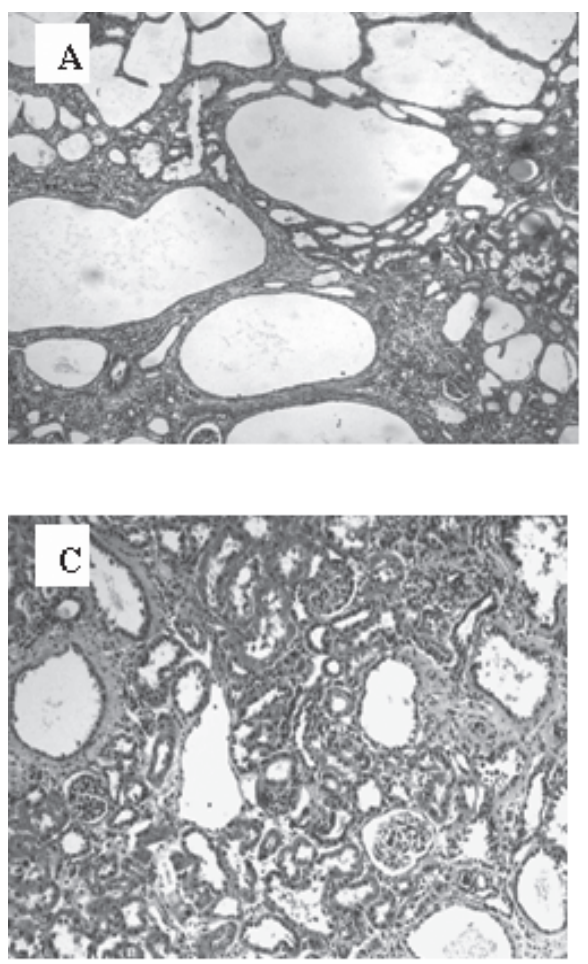

TABLE 2

Effects of MMF, rapamycin and combination therapy on interstitial inflammation and fibrosis of $\mathrm{Cy} /+$ rats

Treatment Inflammatory index, $\%$ Fibrosis index, $\%$

\begin{tabular}{lcc} 
Control & $15.7 \pm 4.1$ & $2.9 \pm 0.73$ \\
MMF & $6.9 \pm 3.6^{\mathrm{b}}$ & $1.50 \pm 0.28^{\mathrm{b}}$ \\
Rapa & $10.9 \pm 3.8^{\mathrm{a} \mathrm{c}}$ & $1.69 \pm 0.54^{\mathrm{a}}$ \\
MMF+Rapa & $7.9 \pm 3.3^{\mathrm{b}}$ & $1.61 \pm 0.66^{\mathrm{b}}$ \\
\hline
\end{tabular}

a $P<0.05$ versus control group, b $P<0.01$ versus control group, c $P<0.05$ versus $\mathrm{MMF}$-treated $\mathrm{Cy} /+$ rats.

\section{DISCUSSION}

ADPKD is a significant cause of renal failure in adults. There are currently no effective treatments. In view of the fact that tubular epithelia proliferation is a central feature of PKD, the use of immunosuppressants is a logical approach. Indeed, methylprednisolone at high doses
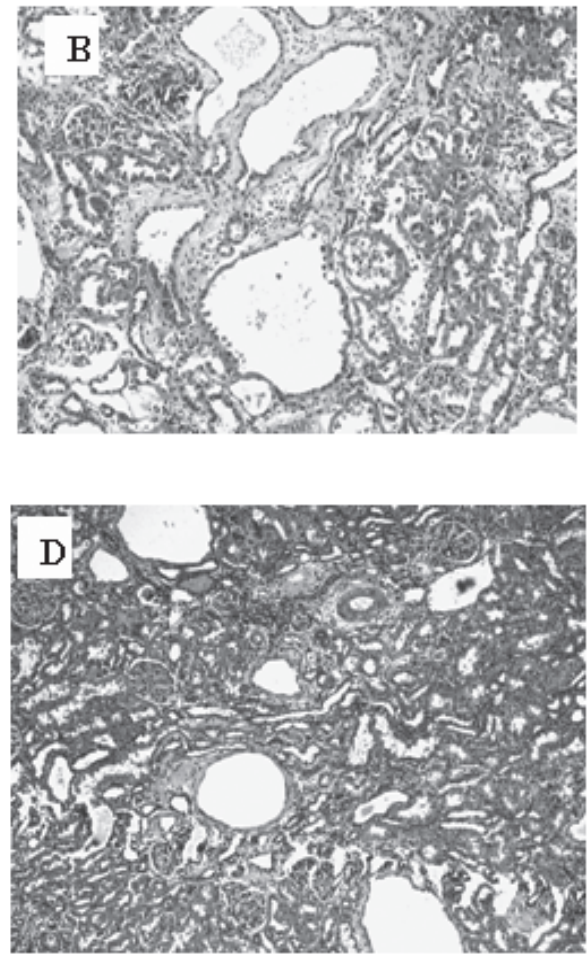

Figure 3: HE-stained sections of kidneys: (A) Vehicle-treated $\mathrm{Cy} /+$ rates, (B) MMF-treated Cy/+ rats, (C) Rapa-treated $\mathrm{Cy} /+$ rats, (D) $\mathrm{MMF}+$ Rapa-treated $\mathrm{Cy} /+$ rats. Original magnification, $\times 200$ 
slowed PKD progression in Cy rats and pcy mice (Gattone et al., 1995). More recently, rapamycin was found to ameliorate $\mathrm{PKD}$ in Han: SPRD rats. In the present study, we have demonstrated, for the first time, the renoprotective effect of another immunosuppressant, MMF in Han: SPRD rats.

Our data confirmed the reports by Tao et al.( Tao et al., 2005) and Wahl PR et al. (Wahl et al., 2006) that rapamycin markedly delayed the loss of renal function and retarded cyst development in Han: SPRD rats. We found that rapamycin decreased the body weight in both $\mathrm{Cy} /+$ and $+/+$ rats despite no apparent difference in food intake, just as the finding of Tao et al., who used a $0.2 \mathrm{mg} / \mathrm{kg} / \mathrm{day}$ dose intraperitoneally. Whereas Wahl PR et al. reported that rapamycin applied through the drinking water, at the same dose as used in our study, did not change body weight. Other studies in rats (Lieberthal et al., 2001) and mice (Ravikumar et al., 2004) also found weight loss caused by rapamycin. However, long-term treatment with rapamycin has not been reported to cause weight loss in adults or children (Tejani et al., 2004). With regard to the effect on body weight, MMF may be more tolerable than rapamycin. Moreover, none of the MMF-treated rats died, while two rapamycin-treated rats died.

It is encouraging that MMF can slow the loss of renal function in Han: SPRD rats. However, this protective effect was less than that of rapamycin. It is possible that MMF is less efficient than rapamycin in slowing PKD progression because the dosage used in this experiment was too low or too high. Thus, a dose-dependent experiment of MMF and treatment for a longer period of time are the subject of ongoing animal studies.

It is interesting that MMF can prevent the increase of BUN and SCr in Han: SPRD rats, but cannot reduce the $2 \mathrm{~K} / \mathrm{TBW}$ ratio, and its effect on cyst growth is mild. On the other hand, interstitial inflammation and fibrosis typically have been observed in Han: SPRD rats in association with the development of renal insufficiency. Our data demonstrates that the inflammatory index and fibosis index of the MMF-treated group were lower than those of the control group. Thus, we suggest the renoprotective effect of MMF in Han: SPRD rats is mainly due to its anti-inflammatory and antifibrotic actions. Several studies have shown a protective effect of MMF on renal tissues in diabetic rat models and 5/6 renal ablation models. In addition to its suppressive effect on lymphocytes, it also suppresses the proliferation of mesangial cells and monocyte/macrophage, limiting the exudation of leukocyte to inflammatory sites, and reducing the accumulation of extracellular matrix (Utimura et al., 2003; Fujihara et al., 2000; Romero et al., 1999). This may help to explain why MMF can slow the loss of renal function in Han: SPRD rats.

Treatment of ADPKD may require the use of multiple types of therapies. It is worth knowing if the combination of MMF and rapamycin is more favorable than either used alone. In the present study, a dose of MMF $20 \mathrm{mg} / \mathrm{kg} /$ day, plus rapamycin $2 \mathrm{mg} /$ $\mathrm{kg} / \mathrm{day}$, was used. However, our data showed that the effect of combination therapy on renal function and CVD was similar to that of using rapamycin alone.

In conclusion, MMF can retard deterioration of renal function in Han: SPRD rats with ADPKD, though its renoprotective effect is less favorable than that of rapamycin. The major effects of MMF in this model appear to be antiinflammation and anti-fibrosis, as well as cyst growth inhibition. Combination therapy does not have more renoprotective effect than rapamycin alone. Further studies are in progress to evaluate the effect of MMF at different doses in different animal models with ADPKD and to explore its mechanism in slowing disease progression.

\section{REFERENCES}

AZZOLA A, HAVRYK A, CHHAJED P, HOSTETTLER K, BLACK J, JOHNSON P, ROTH M, GLANVILLE A, TAMM M (2004). Everolimus and mycophenolate mofetil are potent inhibitors of fibroblast proliferation after lung transplantation. Transplantation 77(2): 275280

BAER PC, GAUER S, HAUSER IA, SCHERBERICH JE, GEIGER H (2000). Effects of mycophenolic acid on 
human renal proximal and distal tubular cells in vitro. Nephrol Dial Transplant 15(2): 184-190

BRAVO Y, QUIROZ Y, FERREBUZ A, VAZIRI ND, RODRÍGUEZ-ITURBE B (2007). Mycophenolate mofetil administration reduces renal inflammation, oxidative stress, and arterial pressure in rats with leadinduced hypertension. Am J Physiol Renal Physiol 293(2): F616-623

COWLEY BD JR, GUDAPATY S, KRAYBILL AL, BARASH BD, HARDING MA, CALVET JP, GATTONE VH 2ND (1993). Autosomal-dominant polycystic kidney disease in the rat. Kidney Int 43(3): 522-534

DAI B, MEI CL (2006). Research on autosomal dominant polycystic kidney disease in China. Chin Med J (Engl) 119(22): 1915-24

DUBUS I, VENDRELY B, CHRISTOPHE I, LABOUYRIE JP, DELMAS Y, BONNET J, COMBE C (2002). Mycophenolic acid antagonizes the activation of cultured human mesangial cells. Kidney Int 62(3): 857 867

FUJIHARA CK, NORONHA IL, MALHEIROS, ANTUNES GR, DE OLIVEIRA IB, ZATZ R (2000). Combined mycophenolate mofetil and losartan therapy arrests established injury in the remnant kidney. J Am Soc Nephrol 11(2): 283-290

GATTONE VH 2ND, COWLEY BD JR, BARASH BD, NAGAO S, TAKAHASHI $\mathrm{H}$, YAMAGUCHI T, GRANTHAM JJ (1995). Methylprednisolone retards the progression of inherited polycystic kidney disease in rodents. Am J Kidney Dis 25(2): 302-313

HAUSER IA, RENDERS L, RADEKE HH, STERZEL RB, GOPPELT-STRUEBE M (1999). Mycophenolate mofetil inhibits rat and human mesangial cell proliferation by guanosine depletion. Nephrol Dial Transplant 14(1) 58-63

LIEBERTHAL W, FUHRO R, ANDRY CC, RENNKE H, ABERNATHY VE, KOH JS, VALERI R, LEVINE JS (2001). Rapamycin impairs recovery from acute renal failure: Role of cell-cycle arrest and apoptosis of tubular cells. Am J Physiol Renal Physiol 281(4): F693-F706

MARTI HP, FREY FJ (2005). Nephrotoxicity of rapamycin: an emerging problem in clinical medicine. Nephrol Dial Transplant 20(1): 13-15

MATHIEU O, CRUZ-ORIVE LM, HOPPELER H, WEIBEL ER (1981). Measuring error and sampling variation in stereology: comparison of the efficiency of various methods for planarimage analysis. J Microsc 121: $75-88$

MORICE MC, SERRUYS PW, SOUSA JE, FAJADET J, BAN HAYASHI E, PERIN M, COLOMBO A, SCHULER G, BARRAGAN P, GUAGLIUMI G, MOLNÀR F, FALOTICO R (2002). A randomized comparison of a sirolimus-eluting stent with a standard stent for coronary revascularization. N Engl J Med 346 (23): $1773-80$

RAVIKUMAR B, VACHER C, BERGER Z, DAVIES JE, LUO S, OROZ LG, SCARAVILLI F, EASTON DF,
DUDEN R, O'KANE CJ, RUBINSZTEIN DC (2004). Inhibition of mTOR induces autophagy and reduces toxicity of polyglutamine expansions in fly and mouse models of Huntington disease. Nat Genet 36(6): 585 595

ROMERO F, RODRÍGUEZ-ITURBE B, PARRA G GONZÁLEZ L, HERRERA-ACOSTA J, TAPIA E (1999). Mycophenolate mofetil prevents the progressive renal failure induced by $5 / 6$ renal ablation in rats. Kidney Int 55(3): 945-955

SERRA AL, KISTLER AD, POSTER D, STRUKER M WÜTHRICH RP, WEISHAUPT D, TSCHIRCH F (2007). Clinical proof-of-concept trial to assess the therapeutic effect of sirolimus in patients with autosomal dominant polycystic kidney disease: SUISSE ADPKD study. BMC Nephrol 8: 13

TAO Y, KIM J, SCHRIER RW, EDELSTEIN CL (2005). Rapamycin markedly slows disease progression in a rat model of polycystic kidney disease. J Am Soc nephrol 16(1): 46-51

TEJANI A, ALEXANDER S, ETTENGER R, LERNER G, ZIMMERMAN J, KOHAUT E, BRISCOE DM (2004). Safety and pharmacokinetics of ascending single doses of sirolimus (Rapamune, rapamycin) in pediatric patients with stable chronic renal failure undergoing dialysis. Pediatr Transplant 8(2): 151-160

UTIMURA R, FUJIHARA CK, MATTAR AL, MALHEIROS DM, NORONHA IL, ZATZ R (2003). Mycophenolate mofetil prevents the development of glomerular injury in experimental diabetes. Kidney Int 63(1): 209-216

UTIMURA R, FUJIHARA CK, MATTAR AL, MALHEIROS DM, NORONHA IL, ZATZ R (2003). Mycophenolate mofetil prevents the development of glomerular injury in experimental diabetes. Kidney Int 63(1): 209-216

VENTURA CG, COIMBRA TM, DE CAMPOS SB, DE CASTRO I, YU L, SEGURO AC (2002). Mycophenolate mofetil attenuates renal ischemia reperfusion injury. J Am Soc Nephrol 13(10): 25242533

WAHL PR, SERRA AL, LE HIR M, MOLLE KD, HALL MN, WÜTHRICH RP (2006). Inhibition of mTOR with sirolimus slows disease progression in Han: SPRD rats with autosomal dominant polycystic kidney disease (ADPKD). Nephrol Dial Transplant 21(3): 598-604

WILSON PD (2004) Polycystic kidney disease. N Engl J Med 350(2): 151-164

WU M, WAHL PR, LE HIR M, WACKERLE-MEN Y, WUTHRICH RP, SERRA AL (2007). Everolimus retards cyst growth and preserves kidney function in a rodent model for polycystic kidney disease. Kidney Blood Press Res 30(4): 253-59

ZHANG T, FU LL, MEI CL (2008). Comparison between effects of mycophenolate mofetil and rapamycin on the proliferation and apoptosis cyst-lining epithelial cells of ADPKD patients. Acad J Secc Mil Med Univ 29(8): 921-922. 